\title{
Giant Uterine Leiomyoma in a Young Woman as an Incidental Finding After a Car Accident: a Case Report
}

\author{
Vladimír Bartoš ${ }^{1, *}$, Peter Korec ${ }^{2}$, Robert Ficek ${ }^{3}$
}

\begin{abstract}
Leiomyomas are the most common benign tumor of the uterus. Occasionally, they may reach an extreme dimension. The authors present a case of a 44-year old woman, who suffered a car accident as a driver of personal motor vehicle. At the hospital, a huge tumor mass filling the entire abdominopelvic cavity was incidentally detected. The patient admitted a progressive abdominal enlargement for the last 5 years. An urgent laparotomy was performed, during which a giant, well-demarcated tumor arising from the uterine body had been disclosed. It was completely surgically removed and sent for histopathology. Grossly, the tumor measured $30 \times 30 \times 20 \mathrm{~cm}$ in the largest diameters and weighed $8.1 \mathrm{~kg}$. The tissue was markedly edematous with foci of massive hemorrhages and contained confluent pseudocystic formations of various sizes, filled with a fluid and fresh blood. Solid foci of rubber consistency were also visible. Microscopic examination revealed a conventional subserous uterine leiomyoma with marked regressive and degenerative changes. Giant uterine leiomyomas occur extremely rare, but because of the often unexpected finding and atypical presentation, they may represent a great diagnostic challenge for both, pathologists and clinicians. At the biopsy examination, a multiple-section sampling is very important to avoid the possibility of underlying malignancy.
\end{abstract}

\section{KEYWORDS}

uterine leiomyoma; giant size; degenerative changes

AUTHOR AFFILIATIONS

${ }^{1}$ Department of Pathology, Faculty Hospital in Žilina, Slovakia

${ }^{2}$ Department of Surgery, Faculty Hospital in Žilina, Slovakia

${ }^{3}$ Department of Gynecology and Obstetrics, Faculty Hospital in Žilina, Slovakia

* Corresponding author: Björnsonova 3/5, Martin, 036 01, Slovakia; e-mail: vladim.bartos@gmail.com

Received: 7 August 2017

Accepted: 12 February 2018

Published online: 2 July 2018

Acta Medica (Hradec Králové) 2018; 61(1): 29-32

https://doi.org/10.14712/18059694.2018.20

(c) 2018 The Authors. This is an open-access article distributed under the terms of the Creative Commons Attribution License (http://creativecommons.org/licenses/by/4.0), which permits unrestricted use, distribution, and reproduction in any medium, provided the original author and source are credited. 


\section{INTRODUCTION}

Leiomyomas are the most common benign tumor of the uterus occuring in 30-50\% of women between $30-50$ years of age (1). In biopsy practice, they are found in up to $75 \%$ of hysterectomy specimens when they are systematically search for (2). Multiple lesions are present in two-thirds of the women with these neoplasms. The etiopathogenesis is still unclear but it seems that hormonal stimulation by estrogen and possibly progesterone plays a key role (2). Based on location they are classified as intramural (the most common form), submucosal and subserosal (2). The size of leiomyomas may vary from diminutive to huge tumors. They are often asymptomatic, but larger lesions produce a variety of clinical symptoms, such as dysmenorrhea, abnormal bleeding, pelvic dyscomfort or pain (2). On occasion, these tumors may reach an extreme size. The authors of the article present an unusual case of a giant uterine leiomyoma in a young woman that was incidentally diagnosed after a car accident.

\section{CASE PRESENTATION}

A 44-year old woman suffered a car accident in the city street as a driver of personal motor vehicle. She was immediately transported to the hospital by Emergency Rescue Service. During transport, the patient was conscious and communicated. A preliminary physical examination showed mild external injuries of the body (mainly contusions of the thorax and abdomen). At the hospital, urgent computed tomography (CT) scan revealed fractures of sternum and the right ribs, contusions of the right lungs and the liver and hemoperitoneum. However, as an incidental finding, a huge tumor mass filling the entire abdominopelvic cavity was detected. It was inhomogeneous, containing multicystic and solid components. Grossly, a woman had visibly enlarged abdomen. The patient admitted a progressive abdominal enlargement for the last 5 years, but she "had no time to visit the doctors". An urgent laparotomy was performed, during which a giant, well-demarcated tumor arising from the uterine body had been disclosed (Figure 1). It grew expansively and compressed the intestines and visceral organs. No tumor implants on the omentum or visceral peritoneum were found. A gynecologist was called ad hoc into the operating room to consult the situation and further steps. The tumor was completely resected and sent for histopathology. Uterus and adnexa were retained in situ. As for traumatic injuries, surface laceration of the liver parenchyma was detected and sutured, as well as hemoperitoneum was evacuated. As the domain of our article is uterine neoplasm, in the next text, we focus on tumor aspects of the case. We only briefly mention, the car-accident related injuries did not have any serious consequences. Additionally it was found out, the patient was a nullipara, but she reported an abortion 15 years ago.

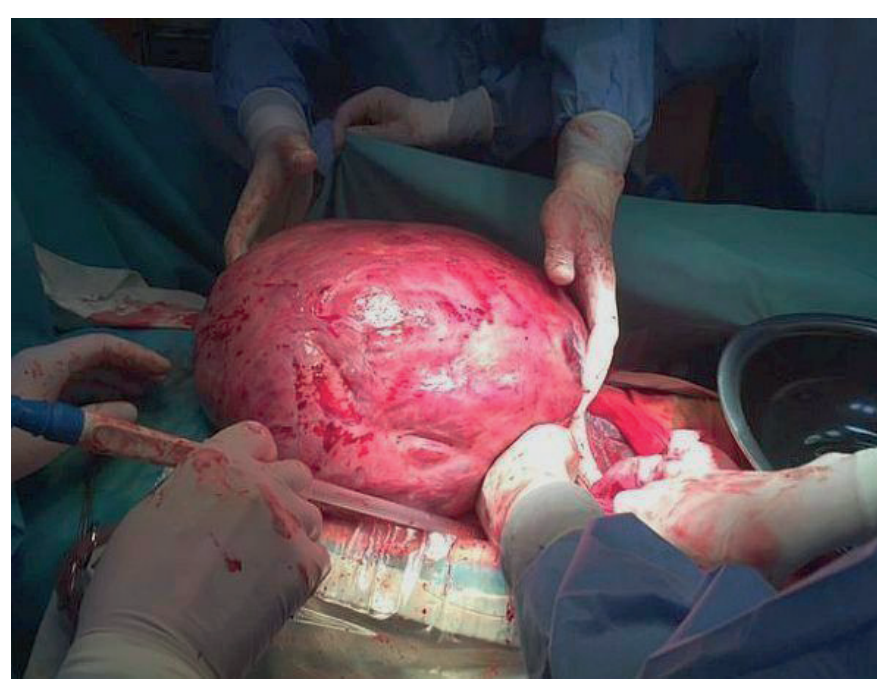

Fig. 1 Giant tumor mass revealed at laparotomy.

\section{MATERIAL AND METHODS}

Macroscopically, the tumor had an irregular shape, it measured $30 \times 30 \times 20 \mathrm{~cm}$ in the largest diameters and weighed $8.1 \mathrm{~kg}$. On the surface, it was smooth and had a gray to gray-yelowish color with multiple small hemorrhages (Figure 2). Serial cut sections revealed very heterogeneous appearence, both of the structure and of the color (Figure 3 ). The tissue was markedly edematous with foci of massive hemorrhages and contained confluent pseudocystic formations of various sizes, filled with a fluid and fresh blood. Furher, solid foci of rubber consistency and brown-yelowish color were also visible. Some of them were hard and calcified. Numerous tissue sections were taken, routinely processed in paraffin blocks (total of 45 blocks), stained with hematoxylin and eosin (H\&E) and investigated in the light microscope. An immunohistochemical analysis was also performed.

\section{RESULTS}

Histopathologic examination identified a conventional subserous uterine leiomyoma with marked regressive changes, prominent edema with pseudocystic degeneration and multifocal fresh hemorrhages. No hemosiderin pigment was detected. Well-preserved tumor tissue was found particularly at the periphery of lesion. It consisted of dense interlacing fascicles of smooth muscle cells without a nuclear pleomorphism or increased mitotic count (Figure 4). Some solid tumor areas showed an extensive hyalinisation and dystrophic calcification. Immunohistochemically, the neoplastic cells were strongly positive for a-smooth muscle actin (clone 1A4, Dako), desmin (clone D33, Dako) (Figure 5) and h-caldesmon (clone h-CD, Dako). Proliferative activity (Ki-67, clone MM1, Leica) did not exceed $1 \%$. No coagulative necroses were detected. There were not found any signs of malignancy. Five days after the first surgery, a laparotomy was repeated at the Depat- 


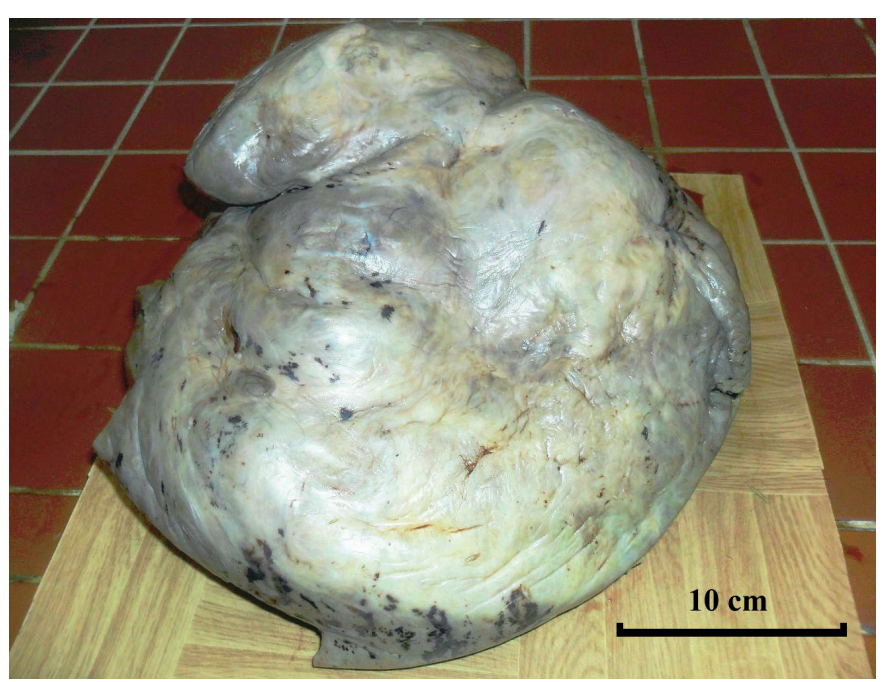

Fig. 2 Tumor after surgical removal (post fixation in formalin).

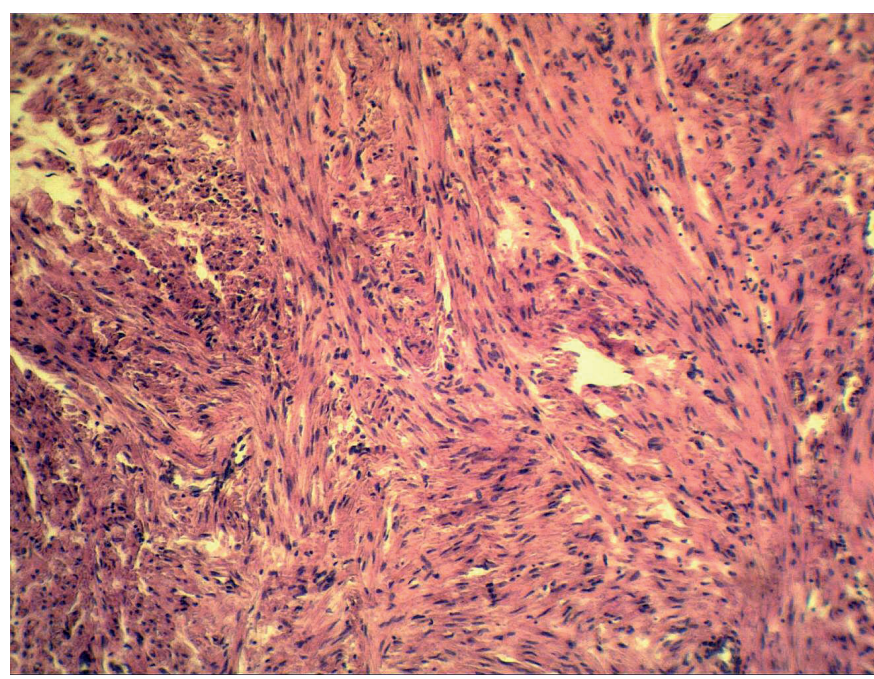

Fig. 4 Histomorphology of conventional leiomyoma (H\&E, magnification 200x).

ment of Gynecology, during which a resection of the uterine fundus containing a solitary intramural nodule $(2.5 \mathrm{~cm}$ in the largest diameter) had been performed. Histologically, this nodular lesion was a conventional leiomyoma. The patient was discharged from the hospital on the 15th day after the first operation. Since she come from another district, at the time of writing this article we had not further informations about her.

\section{DISCUSSION}

Leiomyomas of the uterus belong to one of the most frequent diagnosis in a routine gynecologic and pathologic practice. These tumors may often reach large size, but such huge lesions as presented in our article are exceedingly rare. Although there is no consensual criterium for the definition of "giant" uterine leiomyoma, we reviewed the

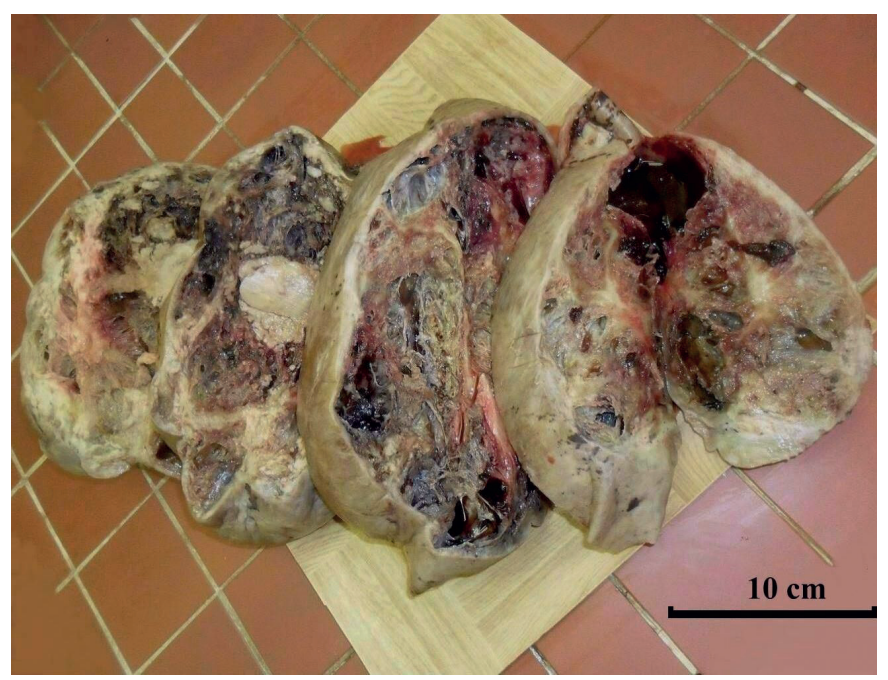

Fig. 3 Transversal sections through tumor (post fixation in formalin).

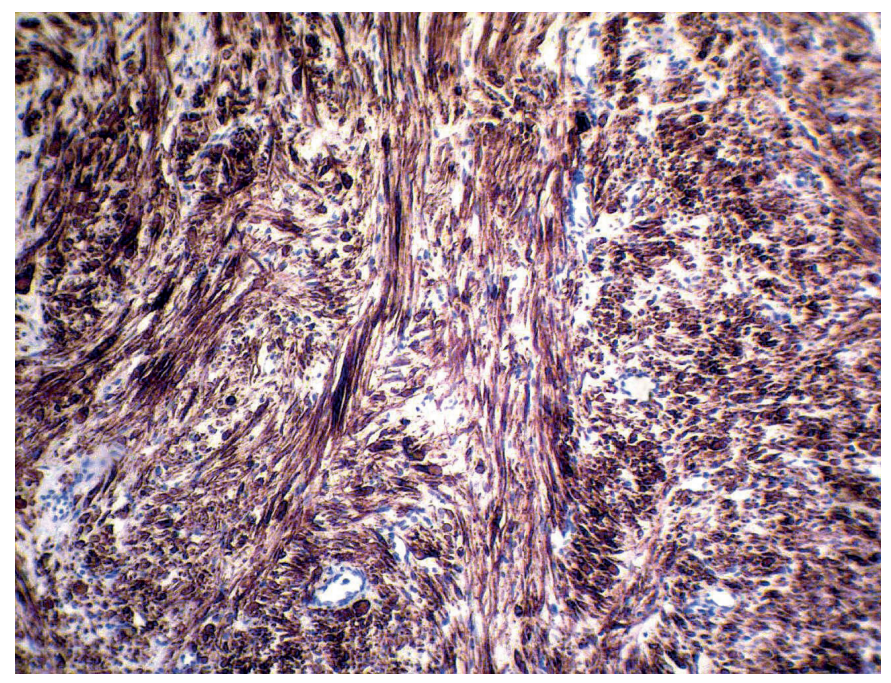

Fig. 5 Diffuse immunoreactivity of tumor for desmin (clone D33, magnification 200x).

recent papers publishing similar case reports using such terminology. They are briefly summarized in Table 1 (references 3-14). According to these literature sources (including our present case), the largest diameter of lesions ranged from 24.2 to $62 \mathrm{~cm}$ and a weight varied from 6.5 to $28.1 \mathrm{~kg}$. They occurred in women between 33-63 years of age (mean 45 years). The most common clinical symptoms were abdominal distention, abnormal uterine bleeding, local pressure and pain. None of these cases was discovered as an incidental finding, which is a great peculiarity of our report. The potential for uterine leiomyomas to grow to an extreme size without significant clinical difficulties is quite notable. This is likely due to the relatively large volume of the abdominal cavity, the distensibility of the abdominal wall and the slow growth rate of these tumors. Especially subserosal lesions may be asymptomatic for a long time and thus, they sometimes become very large before the patient becomes aware of them. 
Tab. 1 A summary of recent case reports describing giant uterine leiomyomas.

\begin{tabular}{|l|l|l|l|}
\hline References & Age & Tumor size & Tumor weight \\
\hline Moris et al. (2014) & 39 years & $62 \times 39 \times 21 \mathrm{~cm}$ & $28.1 \mathrm{~kg}$ \\
\hline Săvulescu et al. (2011) & 45 years & $33 \times 28 \times 22 \mathrm{~cm}$ & $18.1 \mathrm{~kg}$ \\
\hline Wroński (2014) & 63 years & $24.2 \times 17.3 \mathrm{~cm}$ & not available \\
\hline Funaki et al. (2013) & 31 years & $40 \times 40 \times 30 \mathrm{~cm}$ & $8 \mathrm{~kg}$ \\
\hline Kalayci et al. (2015) & 49 years & $33 \times 25 \mathrm{~cm}$ & not available \\
\hline Rahman et al. (2016) & 46 years & $43 \times 32 \times 23 \mathrm{~cm}$ & $11.6 \mathrm{~kg}$ \\
\hline Reshmy et al. (2015) & 50 years & $30 \times 28 \mathrm{~cm}$ & not available \\
\hline Ramteke et al. (2016) & 40 years & $26 \times 23 \times 18 \mathrm{~cm}$ & $6.5 \mathrm{~kg}$ \\
\hline Aydin et al. (2013) & 58 years & $33 \times 20 \times 18 \mathrm{~cm}$ & not available \\
\hline Steward et al. (2011) & 33 years & $31 \times 26 \times 14 \mathrm{~cm}$ & $11.6 \mathrm{~kg}$ \\
\hline Müller \& Břeský (2016) & 42 years & $>30 \mathrm{~cm}$ & $15.6 \mathrm{~kg}$ \\
\hline Rajender Prasad et al. (2015) & 45 years & $33 \times 28 \times 22 \mathrm{~cm}$ & $20 \mathrm{~kg}$ \\
\hline present case & 44 years & $35 \times 30 \times 20 \mathrm{~cm}$ & $8.1 \mathrm{~kg}$ \\
\hline
\end{tabular}

Larger uterine leiomyomas are frequently accompanied by prominent regressive and degenerative changes. Hyaline fibrosis and edema of tumor tissue are the most common one and are observed in up to $60 \%$ and $50 \%$ of all microscopically investigated leiomyomas of the uterus, respectively (2). Approximatelly $10 \%$ of them displayes significant areas of hemorrhages (2). Pseudocystic degeneration occurs in about $4 \%$ of the cases (2) and it is usually extreme sequelae of edema. Dystrophic calcification may be found in $4 \%$ of all uterine leiomyomas (2), especially within fibrohyalinized regions. It is understandable, these changes become more prominent in huge tumors that have been growing for a long time. As a tumor progressively enlarges, it outgrows its blood supply, resulting in various types of degeneration. As a result they may create heterogeneous or unusual microscopic appearances that contribute to diagnostic confusion.

In conclusion, giant uterine leiomyomas occur extremely rare, but because of the often unexpected finding and atypical presentation, they may represent a great diagnostic challenge for both, pathologists and clinicians. At the biopsy examination, a multiple-section sampling is very important to avoid the possibility of underlying malignancy. A minimal sampling should include one tissue section per each $1 \mathrm{~cm}$ of tumor diameter. In our case, despite numerous tissue specimens investigated, no histologic features of malignancy were found.

\section{ACKNOWLEDGEMENTS}

The authors would like to thank all physicians from Faculty Hospital in Žilina, who participated on treatment and clinical management of the patient.

\section{REFERENCES}

1. Sklářová R. Klasifikace děložní myomatozy a její diagnostika ve vztahu k reprodukčním dysfunkcím. Prakt Gyn 2014; 18: 259-64.

2. Zaloudek C, Hendrickson MR. Mesenchymal Tumors of the Uterus. In: Kurman RJ (Ed). Blaustein's Pathology of the Female Genital Tract. 5th Edition, Springer Verlag, 2002: 564-78.

3. Moris D, Vernadakis S. Giant uterine leiomyoma mimicking pregnancy. Mayo Clin Proc, 2014; 89: e53-4.

4. Săvulescu F, Iordache I, Albiţa O, et al. Giant uterine leiomyoma. Chirurgia (Bucur) 2011; 106: 665-8.

5. Wroński K. Giant uterine leiomyoma - case report and review of literature. New Medicine 2014; 18: 89-91.

6. Funaki K, Fukunishi H, Tsuji Y, Maeda T, Takahashi T. Giant cystic leiomyoma of the uterus occupying the retroperitoneal space. J Radiol Case Rep 2013; 7: 35-40.

7. Kalayci TO, Akath AN, Sönmezgöz F, Şamdancı ET. A giant subserosal uterine leiomyoma mimicing and abdominal mass: multomodal imaging data. Acta Medica Iranica 2015; 53: 246-9.

8. Rahman H, Sharma BK, Khalda E, Pathak R, Dubey S. Giant leiomyoma uterus with myomatous erythrocytosis syndrome: A rare case report. J Cases Obstet Gynecol 2016; 3: 88-91.

9. Reshmy JR, Bharti M, Rahul R. Giant cystic leiomyoma masquerading as ovarian tumour - case report. Sch J Med Case Rep 2015; 3: 608-10.

10. Ramteke S, Joshi P, Zararia A, Dharmale D. Fast growing giant intramural leiomyoma - a case report. Int J Health Sci Res 2016; 6: 542-5.

11. Aydin C, Eriş S, Yalçin Y, Sen Selim H. A giant cystic leiomyoma mimicking an ovarian malignancy. Int J Surg Case Rep 2013; 4: 1010-2.

12. Steward RG, Denhartog HW, Katz AR. Giant uterine leiomyomata. Fertil Steril 2011; 95: 1121.e15-7.

13. Müller R, Břeský P. Obrovský deložní myom - kazuistika. Čes Gynek 2016; 81: 71-5.

14. Rajender Prasad S, Nikhil S, Kumud S, Akanksha S, Atul J, Akshay P. Giant uterine leiomyoma and review of literature. Int J Med Sci Clin Invent 2015; 2: 640-4. 